\title{
Perbandingan Algoritma Boyer-Moore dan Brute Force pada Pencarian Kamus Besar Bahasa Indonesia Berbasis Android
}

\author{
Candra Irawan', Mudafiq Riyan Pratama ${ }^{2}$ \\ ${ }^{1}$ Teknik Informatika, Universitas Muhammadiyah Jember, candwan66@gmail.com \\ ${ }^{2}$ Politeknik Negeri Jember, mudafiq.riyan@polije.ac.id
}

\begin{tabular}{l} 
Keywords: \\
\hline String Matching, \\
Boyer-Moore, \\
Brute Force, \\
Searching, \\
KBBI,
\end{tabular}

\begin{abstract}
String matching is an algorithm for matching a text to another text or also known as a text search. There are several algorithms that can be used for string matching, including the Boyer-Moore algorithm and the Brute Force algorithm. The BoyerMoore algorithm is a string matching algorithm published by Robert S. Boyer and J. Strother Moore in 1977. This algorithm is considered the most efficient algorithm in general applications. The Boyer-Moore algorithm starts matching characters from the pattern on the right. While the Brute Force algorithm is an algorithm that matches a pattern with all text between 0 and $n-m$ to find the existence of a pattern in the text. These two algorithms have different patterns in the search process. In this article, a comparative analysis of the performance of the Boyer-Moore and Brute Force algorithms is carried out in a case study of the search for the Big Indonesian Dictionary (KBBI) based on Android. The search process is carried out by searching based on words and word descriptions. The results of this study indicate that the criteria for running time, the Brute Force algorithm is faster than the Boyer-Moore algorithm with the total running time of the Brute Force algorithm is $168.3 \mathrm{~ms}$ in words, $6994.16 \mathrm{~ms}$ in word descriptions, while the Boyer-Moore algorithm for running time reached 304.7 $\mathrm{ms}$ on the word, $8654.77 \mathrm{~ms}$ on the word description. In the testing criteria based on related keywords, the two algorithms can display the same list of related keywords.
\end{abstract}

\begin{tabular}{l} 
Kata Kunci \\
\hline String Matching, \\
Boyer-Moore, \\
Brute Force, \\
Pencarian, \\
KBBI
\end{tabular}

\begin{abstract}
ABSTRAK
String matching merupakan algoritma untuk pencocokan suatu teks terhadap teks lain atau juga disebut sebagai pencarian teks. Ada beberapa algoritma yang dapat digunakan untuk string matching, diantaranya algoritma Boyer-Moore dan Brute Force. Algoritma Boyer-Moore adalah salah satu algoritma pencocokan string yang dipublikasikan oleh Robert S. Boyer dan J. Strother Moore pada tahun 1977. Algoritma ini dianggap sebagai algoritma yang paling efisien pada aplikasi umum. Algoritma Boyer-Moore memulai pencocokan karakter dari pattern sebelah kanan. Sedangkan algoritma Brute Force adalah algoritma yang mencocokkan pattern dengan semua teks antara 0 dan n-m untuk menemukan keberadaan pattern dalam teks. Kedua algoritma ini memiliki pola yang berbeda dalam proses pencariannya. Pada artikel ini dilakukan analisa perbandingan kinerja algoritma Boyer-Moore dan Brute Force pada studi kasus pencarian Kamus Besar Bahasa Indonesia (KBBI) berbasis Android. Proses pencarian dilakukan dengan melakukan pencarian berdasarkan kata dan deskripsi kata. Hasil penelitian ini menunjukkan bahwa pada kriteria running time, algoritma Brute Force lebih cepat dibandingkan algoritma Boyer-Moore dengan total running time algoritma Brute Force adalah $168,3 \mathrm{~ms}$ pada kata, $6994,16 \mathrm{~ms}$ pada deskripsi kata, sedangkan pada algoritma Boyer-Moore untuk running time mencapai 304,7 ms pada kata, $8654,77 \mathrm{~ms}$ pada deskripsi kata. Pada kriteria pengujian berdasarkan keyword related, kedua algoritma dapat menampilkan daftar keyword related yang sama.
\end{abstract}

\author{
Korespondensi Penulis: \\ Mudafiq Riyan Pratama \\ Politeknik Negeri Jember \\ Jl. Mastrip 164 Jember \\ Email: mudafiq.riyan@polije.ac.id
}




\section{PENDAHULUAN}

String matching merupakan suatu algoritma yang digunakan untuk pencocokan suatu teks terhadap teks lain atau juga disebut sebagai pencarian teks. Ada beberapa algoritma yang dapat digunakan untuk string matching, diantaranya adalah algortima Boyer-Moore [1] dan Brute Force. Algoritma Boyer-Moore adalah salah satu algoritma pencarian string yang dipublikasikan oleh Robert S. Boyer dan J. Strother Moore pada tahun 1977. Algoritma BoyerMoore dianggap sebagai salah satu algoritma yang paling efisien untuk aplikasi pencocokan pola umum. Ia mampu mengenali dan melewati area tertentu dalam teks yang tidak ditemukan kecocokan [2]. Ide dibalik algoritma ini adalah bahwa dengan memulai pencocokkan karakter dari kanan, dan bukan dari kiri, maka akan lebih banyak informasi yang didapat [3].

Sedangkan Algoritma Brute Force adalah algoritma pattern matching yang paling sederhana, dan pencarian Brute Force bersifat left-to-right, yakni dari kiri ke kanan, sehingga pattern akan dicocokkan huruf per huruf dalam sebuah teks, dan ketika sebuah huruf dalam pattern yang ingin dicocokkan tidak sesuai dengan salah satu huruf dalam teks, maka pencarian akan diulang dan dimulai pada huruf teks selanjutnya [4]. Kedua algoritma memiliki cara pencarian yang berbeda, sehingga tentunya akan menghasilkan kecepatan dan hasil yang berbeda.

Dengan adanya perbedaan cara kerja kedua algoritma tersebut, maka perlu adanya analisa yang membandingkan kinerja kedua algoritma tersebut dalam pencarian kata pada KBBI (Kamus Besar Bahasa Indonesia). KBBI ini menjadi pilihan karena berisi lexicon atau kamus kata yang jumlahnya besar, sehingga semakin banyak data yang dicari, akan terlihat kinerja dari masing-masing algoritma tersebut.

\section{METODE PENELITIAN}

\subsection{Flowchart Sistem}

Algoritma yang dipilih pada penelitian ini ada dua, yaitu algoritma Boyer-Moore dan Brute Force. Flowchart dari masing-masing algoritma tersebut digambarkan pada Gambar 1 dan Gambar 2.

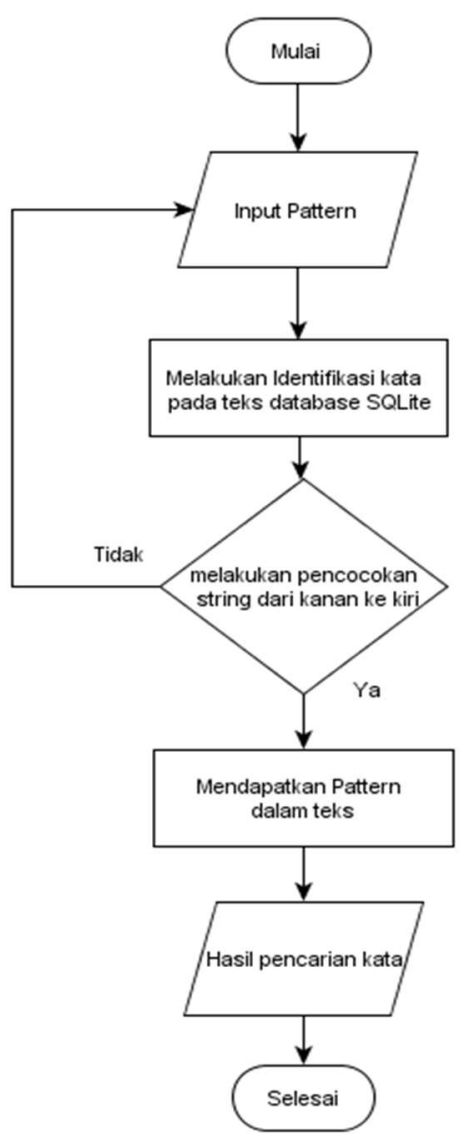

Gambar 1. Flowchart Boyer-Moore

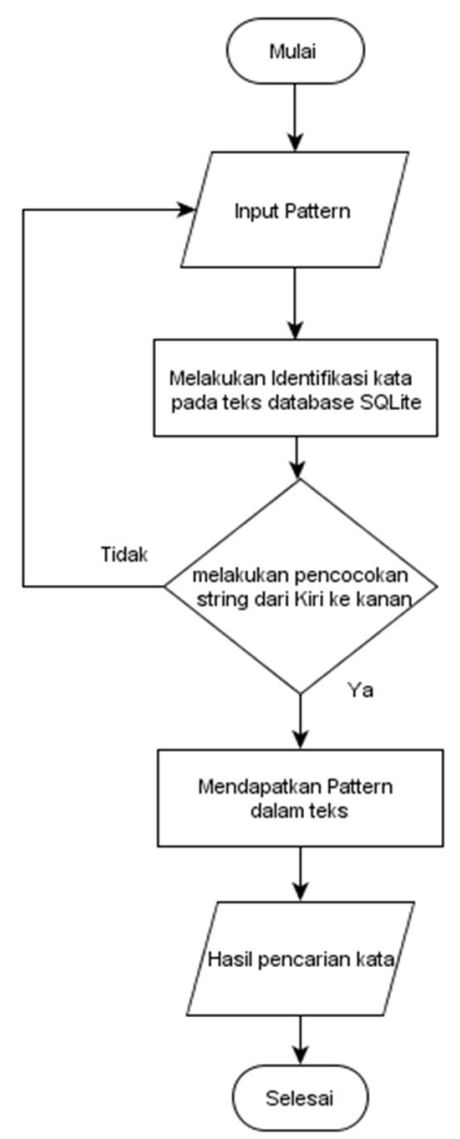

Gambar 2. Flowchart Brute Force

Dari Gambar 1 di atas, dijelaskan alur proses pencarian teks menggunakan algoritma Boyer-Moore, yaitu pertama user memasukkan pattern berupa karakter yang ingin dicari di database KBBI. Kemudian melakukan identifikasi kata yang ada di database dengan melakukan pencocokan string dari kanan ke kiri sesuai dengan inputan pattern yang diinginkan oleh user. Proses tersebut melakukan looping atau perulangan sampai semua data di database ditemukan kecocokan dengan pattern yang dicari. Dan sistem akan menampilkan output dari hasil pencarian. Berikut ini contoh alur dari algoritma Boyer-Moore [5] 


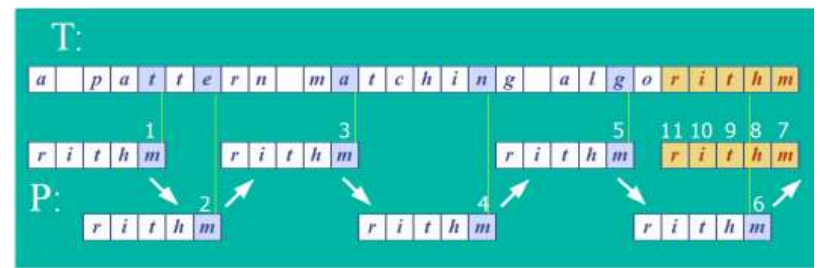

Gambar 3. Contoh alur dari algoritma Boyer-Moore adalah [6]:

Secara sistematis, langkah-langkah yang dilakukan algoritma Boyer-Moore pada saat mencocokkan string

1. Algoritma Boyer-Moore mulai mencocokkan pattern pada awal teks.

2. Dari kanan ke kiri, algoritma ini akan mencocokkan karakter per karakter pattern dengan karakter di teks yang bersesuaian, sampai salah satu kondisi berikut dipenuhi:

a. Karakter di pattern dan di teks yang dibandingkan tidak cocok (mismatch).

b. Semua karakter di pattern cocok. Kemudian algoritma akan memberitahukan penemuan di posisi ini.

3. Algoritma kemudian menggeser pattern dengan memaksimalkan nilai penggeseran good-suffix dan penggeseran bad-character, lalu mengulangi langkah 2 sampai pattern berada di ujung teks.

Sedangkan pada Gambar 2 merupakan penjelasan alur dari algoritma Brute Force, yaitu user memasukkan pattern yang ingin dicari, kemudian sistem melakukan pembacaan pattern pada database KBBI yang dilakukan pencocokan string dari kiri ke kanan. Sistem akan melakukan looping pencocokan string dan menampilkan data yang sesuai dengan pattern yang dicari. Secara sistematis, langkah-langkah yang dilakukan algoritme brute force pada saat mencocokkan string adalah [4]:

1. Algoritme Brute Force mulai mencocokkan pattern pada awal teks.

2. Dari kiri ke kanan, algoritma ini akan mencocokkan karakter per karakter pattern dengan karakter di teks yang bersesuaian, sampai salah satu kondisi berikut dipenuhi:

a. Karakter di pattern dan di teks yang dibandingkan tidak cocok (mismatch).

b. Semua karakter di pattern cocok. Kemudian algoritma akan memberitahukan penemuan di posisi ini.

3. Algoritma kemudian terus menggeser pattern sebesar satu ke kanan, dan mengulangi langkah ke-2 sampai pattern berada di ujung teks.

\subsection{Skenario Pengujian}

Pengujian dilakukan untuk membandingkan kinerja dari algoritma Boyer-Moore dan Brute Force yang dilakukan dengan dua skenario yaitu pencarian pada kata dan pencarian pada deskripsi kata yang masing-masing dilakukan pengujian berdasarkan running time (kecepatan proses pencarian) dan keyword related (kata yang muncul dari hasil pencarian).

\section{HASIL DAN ANALISIS}

Pencarian dilakukan berdasarkan string pattern yang diketikkan pada kolom pencarian yang kemudian string tersebut dicocokkan pada database KBBI yang berjumlah 17.000 kata. Setiap proses akan dilakukan pencarian pada kata dan deskripsi kata yang telah tersedia pada database KBBI, kemudian dihitung jumlah running time dan keyword related nya. Hasil pengujian tersebut dipaparkan pada subbab berikut ini:

\subsection{Hasil Pengujian Pencarian Kata dengan Algoritma Boyer-Moore}

Pada pengujian ini dilakukan pencarian dengan 20 kata kunci menggunakan algoritma Boyer-Moore. Dan setiap kata kunci yang dicari akan melakukan pencarian pada data kata dan deskripsi kata yang tersedia di KBBI. Hasil dari pengujian ini dipaparkan pada tabel di bawah ini.

Tabel 1. Hasil pengujian dengan algoritma Boyer-Moore

\begin{tabular}{|c|l|c|c|c|c|}
\hline \multirow{2}{*}{ No. } & \multirow{2}{*}{ Pattern } & \multicolumn{2}{|c|}{ Running Time (ms) } & \multicolumn{2}{c|}{ Keyword related } \\
\cline { 3 - 6 } & & Kata & Deskripsi & Kata & Deskripsi \\
\hline 1 & an & 234,08 & 2658,62 & 2890 & 16459 \\
\hline 2 & me & 33,93 & 2219,75 & 857 & 12091 \\
\hline 3 & di & 22,38 & 1696,5 & 618 & 10162 \\
\hline 4 & dia & 2,83 & 600,93 & 64 & 1909 \\
\hline 5 & aku & 3,35 & 530,46 & 79 & 1705 \\
\hline 6 & aki & 2,43 & 618,3 & 56 & 1875 \\
\hline 7 & auto & 0,57 & 0,53 & 14 & 7 \\
\hline 8 & beli & 0,99 & 119,73 & 27 & 367 \\
\hline 9 & buku & 0,43 & 64,91 & 4 & 252 \\
\hline 10 & nasi & 1,58 & 101,52 & 48 & 512 \\
\hline
\end{tabular}




\begin{tabular}{|c|l|c|c|c|c|}
\hline 11 & verbal & 0,25 & 2,09 & 7 & 11 \\
\hline 12 & pasca & 0,42 & 0,32 & 11 & 5 \\
\hline 13 & pramu & 0,36 & 2,68 & 10 & 23 \\
\hline 14 & humor & 0,18 & 0,46 & 4 & 6 \\
\hline 15 & profesi & 0,24 & 5,23 & 4 & 36 \\
\hline 16 & prospek & 0,18 & 0,22 & 4 & 2 \\
\hline 17 & spesial & 0,19 & 0,28 & 4 & 2 \\
\hline 18 & seismogra & 0,12 & 0,13 & 2 & 1 \\
\hline 19 & perempuan & 0,08 & 31,93 & 1 & 245 \\
\hline 20 & harmonika & 0,11 & 0,18 & 1 & 2 \\
\hline \multicolumn{2}{|l|}{ Total } & $\mathbf{3 0 4 , 7}$ & $\mathbf{8 6 5 4 , 7 7}$ & $\mathbf{4 7 0 5}$ & $\mathbf{4 5 6 7 2}$ \\
\hline \multicolumn{2}{|l|}{ Rata-rata } & $\mathbf{1 5 , 2 3 5}$ & $\mathbf{4 3 2 , 7}$ & \multicolumn{2}{c}{} \\
\cline { 2 - 3 }
\end{tabular}

Dari tabel di atas, pada 20 kali percobaan pencarian pattern, diperoleh total running time pada pencarian kata adalah $304.7 \mathrm{~ms}$, sedangkan total running time pada pencarian deskripsi adalah $8654.77 \mathrm{~ms}$. Hasil keyword related yang ditemukan pada kata berjumlah total 4705 dan pada deskripsi berjumlah total 45672 kata.

\subsection{Hasil Pengujian Pencarian Kata dengan Algoritma Brute Force}

Pengujian dilakukan dengan pattern yang sama seperti pengujian pada subbab 3.1 diatas. Dan hasil yang didapat dengan menggunakan algoritma Brute Force dapat dilihat pada tabel di bawah ini

Tabel 2. Hasil pengujian dengan algoritma Brute Force

\begin{tabular}{|c|l|c|c|c|c|}
\hline \multirow{2}{*}{ No. } & \multirow{2}{*}{ Pattern } & \multicolumn{2}{c|}{ Running Time (ms) } & \multicolumn{2}{c|}{ Keyword related } \\
\cline { 3 - 6 } & & Kata & Deskripsi & Kata & Deskripsi \\
\hline 1 & an & 131,3 & 2409,29 & 2890 & 16459 \\
\hline 2 & me & 16,84 & 1045,81 & 857 & 12091 \\
\hline 3 & di & 12,24 & 1607,88 & 618 & 10162 \\
\hline 4 & dia & 1,74 & 550,62 & 64 & 1909 \\
\hline 5 & aku & 1,76 & 458,6 & 79 & 1705 \\
\hline 6 & aki & 1,31 & 514,98 & 56 & 1875 \\
\hline 7 & auto & 0,27 & 0,56 & 14 & 7 \\
\hline 8 & beli & 0,57 & 155,01 & 27 & 367 \\
\hline 9 & buku & 0,21 & 82,44 & 4 & 252 \\
\hline 10 & nasi & 0,78 & 100,24 & 48 & 512 \\
\hline 11 & verbal & 0,15 & 2,21 & 7 & 11 \\
\hline 12 & pasca & 0,26 & 0,29 & 11 & 5 \\
\hline 13 & pramu & 0,2 & 2,65 & 10 & 23 \\
\hline 14 & humor & 0,12 & 0,43 & 4 & 6 \\
\hline 15 & profesi & 0,11 & 9,57 & 4 & 36 \\
\hline 16 & prospek & 0,13 & 0,35 & 4 & 2 \\
\hline 17 & spesial & 0,12 & 0,21 & 4 & 2 \\
\hline 18 & seismogra & 0,1 & 0,15 & 2 & 1 \\
\hline 19 & perempuan & 0,08 & 51,69 & 1 & 245 \\
\hline 20 & harmonika & 0,06 & 0,18 & 1 & 2 \\
\hline \multicolumn{2}{r}{ Total } & $\mathbf{1 6 8 , 3}$ & $\mathbf{6 9 9 4 , 1 6}$ & $\mathbf{4 7 0 5}$ & $\mathbf{4 5 6 7 2}$ \\
\hline \multicolumn{2}{|c|}{ Rata-rata } & $\mathbf{8 , 4 1 5}$ & $\mathbf{3 4 9 , 7}$ & & \\
\hline
\end{tabular}

Dari tabel di atas, pada 20 kali percobaan pencarian pattern, diperoleh total running time pada pencarian kata adalah $168.3 \mathrm{~ms}$, sedangkan total running time pada pencarian deskripsi adalah $6994.16 \mathrm{~ms}$. Hasil keyword related yang ditemukan pada kata berjumlah total 4705 dan pada deskripsi berjumlah total 45672 kata.

\subsection{Hasil Pengujian Pencarian Kata Palindrom dengan Algoritma Boyer-Moore dan Brute Force}

Kata palindrom merupakan kata yang dapat dibaca dengan sama, baik dari kanan maupun dari kiri. Pengujian ini perlu dilakukan untuk membedakan antara algoritma Boyer-Moore dan Brute Force karena kedua algoritma ini memiliki perbedaan arah penelusurannya, yaitu Boyer-Moore melakukan penelusuran dari kanan ke kiri, sedangkan Brute Force melakukan penelusuran dari kiri ke kanan. Pengujian dilakukan pada 5 kali percobaan kata. Hasil dari pengujian ini dapat dilihat pada tabel di bawah ini.

Tabel 3. Hasil pengujian pencarian kata palindrom dengan algoritma Boyer-Moore dan Brute Force Running Time (ms) 


\begin{tabular}{|c|l|c|c|c|c|c|c|}
\hline \multirow{2}{*}{ No } & \multirow{2}{*}{ Pattern } & \multicolumn{2}{|c|}{ Boyer-Moore } & \multicolumn{2}{c|}{ Brute Force } & \multicolumn{2}{c|}{$\begin{array}{c}\text { Keyword Related Boyer- } \\
\text { Moore dan Brute Force }\end{array}$} \\
\cline { 3 - 8 } & & Kata & Deskripsi & Kata & Deskripsi & Kata & Deskripsi \\
\hline 1 & ada & 5,34 & 555,21 & 2,63 & 462,69 & 157 & 3499 \\
\hline 2 & apa & 3,56 & 569,19 & 1,86 & 496,97 & 100 & 4228 \\
\hline 3 & taat & 0,17 & 6,49 & 0,8 & 5,48 & 2 & 26 \\
\hline 4 & makam & 0,47 & 117,75 & 0,33 & 100,4 & 5 & 833 \\
\hline 5 & radar & 0,13 & 2,96 & 0,8 & 2,93 & 2 & 13 \\
\hline \multicolumn{2}{|r|}{ Total } & $\mathbf{9 , 6 7}$ & $\mathbf{1 2 5 1 , 6}$ & $\mathbf{6 , 4 2}$ & $\mathbf{1 0 6 8 , 4 7}$ & $\mathbf{2 6 6}$ & $\mathbf{8 5 9 9}$ \\
\hline \multicolumn{2}{|c|}{ Rata-rata } & $\mathbf{1 , 9 3}$ & $\mathbf{2 5 0 , 3 2}$ & $\mathbf{1 , 2 8}$ & $\mathbf{2 1 3 , 6 9}$ & & \\
\end{tabular}

Dapat dilihat pada tabel di atas, hasil pencarian kata palindrom menunjukkan bahwa algoritma Brute Force tetap lebih unggul dibandingkan algoritma Boyer-Moore dari sisi running time, yaitu running time kata pada Brute Force totalnya $6.42 \mathrm{~ms}$, sedangkan Boyer-Moore totalnya $9.67 \mathrm{~ms}$. Pun demikian pada total running time pada hasil pencarian deskripsi juga lebih cepat algoritma Brute Force dibandingkan Boyer-Moore. Sedangkan berdasarkan keyword related didapatkan hasil yang sama antara kedua algoritma tersebut.

\subsection{Analisa Perbandingan Algoritma Boyer-Moore dan Brute Force}

Setelah melakukan pengujian pada masing-masing algoritma, perbandingan antara kedua algoritma tersebut dapat dilihat pada gambar di bawah ini.

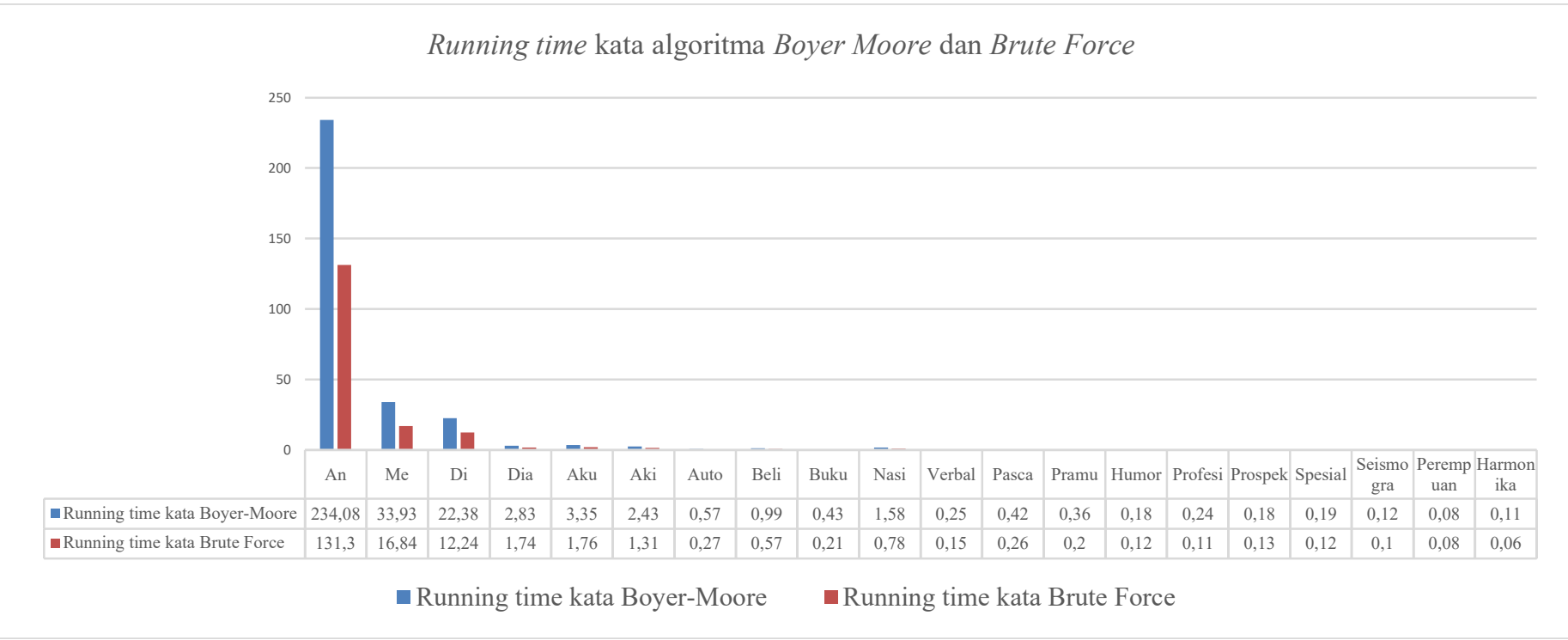

Gambar 4. Grafik perbandingan running time pencarian kata pada algoritma Boyer-Moore dan Brute Force 
Running time deskripsi algoritma Boyer Moore dan Brute Force

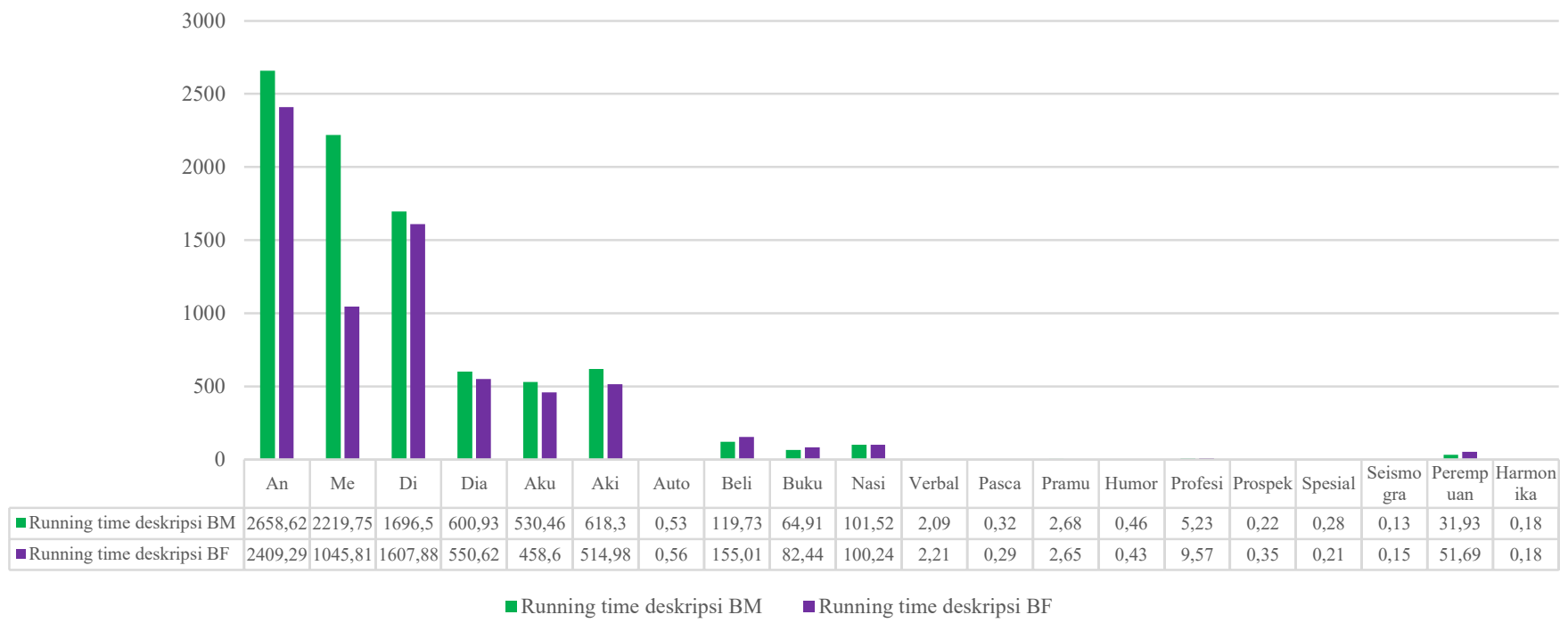

Gambar 5. Grafik perbandingan running time pencarian deskripsi pada algoritma Boyer-Moore dan Brute Force

Berdasarkan grafik di atas, dapat dilihat bahwa running time pada pencarian kata maupun deskripsi, secara garis besar, algoritma Brute Force lebih cepat dibandingkan Boyer-Moore, meskipun pada beberapa kata kunci berikut: “auto", "beli", “buku”, "verbal”, "profesi”, "prospek”, “seismogra”, “perempuan” pada pencarian deskripsi, algoritma Brute Force memiliki running time yang lebih lama dibandingkan Boyer-Moore. Untuk lebih memastikan mana yang lebih cepat diantara kedua algoritma tersebut, maka dapat dilihat grafik total running time pada Gambar 5 di bawah ini.

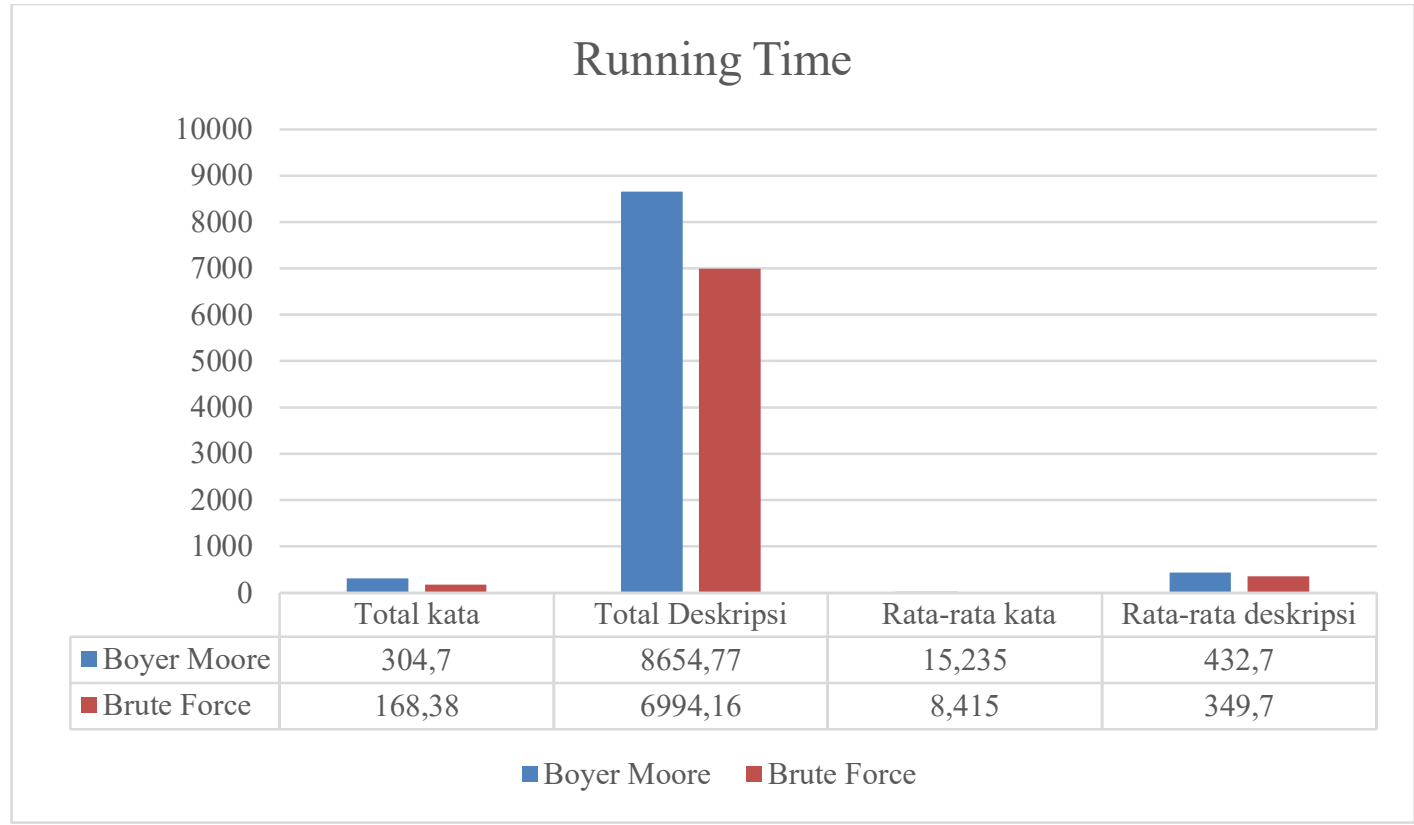

Gambar 6. Total dan rata-rata running time algoritma Boyer-Moore dan Brute Force

Antara algoritma Boyer-Moore dan Brute Force terdapat perbedaan yang cukup signifikan dari sisi running time. Berdasarkan running time, bisa disimpulkan bahwa algoritma Brute Force dengan total running time $168.3 \mathrm{~ms}$ (pada pencarian kata) dan $6994.16 \mathrm{~ms}$ (pada pencarian deskripsi) lebih cepat dibandingkan algoritma Boyer-Moore yang total running time nya $304.17 \mathrm{~ms}$ (pada pencarian kata) dan $8654.77 \mathrm{~ms}$ (pada pencarian deskripsi). Sedangkan dari sisi keyword related, kedua algoritma memiliki hasil yang sama.

Dari grafik diatas dapat disimpulkan bahwa algoritma Brute Force memiliki nilai total dan rata-rata running time yang lebih rendah dibandingkan dengan algoritma Boyer-Moore, artinya bahwa algoritma Brute Force lebih cepat dibandingkan dengan algoritma Boyer-Moore. Algoritma Brute Force lebih cepat karena alurnya pencariannya 
dari kiri ke kanan dan akan berhenti ketika telah ditemukan kesesuaian antara pattern dengan teks. Dikuatkan lagi ketika dilakukan pengujian pada pattern palindrom, pencarian dengan Brute Force tetap lebih cepat dibandingkan Boyer-Moore.

Sedangkan dari sisi keyword related, kedua algoritma dapat menemukan semua kata yang dicari dengan jumlah yang sama, artinya kedua algoritma tersebut memiliki kualitas yang sama mengenai hasil pencarian. Sehingga tidak ada perbedaan kinerja kedua algoritma tersebut berdasarkan keyword related.

\section{KESIMPULAN}

Dari hasil penelitian ini, dapat disimpulkan beberapa poin berikut:

1. Algoritma Brute Force melakukan pencocokan pattern dengan teks dari kiri-ke-kanan, sedangkan algoritma Boyer-Moore melakukan pencocokan dari kanan-ke-kiri.

2. Algoritma Brute Force memiliki nilai total dan rata-rata running time yang lebih rendah dibandingkan dengan algoritma Boyer-Moore, artinya bahwa algoritma Brute Force lebih cepat dibandingkan dengan algoritma Boyer-Moore. Algoritma Brute Force lebih cepat karena alurnya pencariannya dari kiri ke kanan dan akan berhenti ketika telah ditemukan kesesuaian antara pattern dengan teks. Dikuatkan lagi ketika dilakukan pengujian pada pattern palindrom, pencarian dengan Brute Force tetap lebih cepat dibandingkan BoyerMoore.

3. Pada algoritma Boyer Moore maupun Brute Force, semakin sedikit karakter pattern yang dicari maka pencariannya semakin lama karena kata yang dicari semakin banyak dan kata yang ditemukan juga semakin banyak, dan semakin banyak karakter pattern yang dicari maka pencariannya semakin cepat karena yang dicari semakin sedikit dan kata yang ditemukan juga semakin sedikit.

4. Dari sisi keyword related, kedua algoritma dapat menemukan semua kata yang dicari dengan jumlah yang sama, artinya kedua algoritma tersebut memiliki kualitas yang sama mengenai hasil pencarian.

\section{REFERENSI}

[1] R. S. Boyer and J. S. Moore, “A Fast String Searching Algorithm,” Commun. ACM, vol. 20, no. 10, pp. 762-772, 1977.

[2] T. Bell, M. Powell, A. Mukherjee, and D. Adjeroh, "Searching BWT compressed text with the Boyer-Moore algorithm and binary search," Data Compression Conf. Proc., vol. 2002-Janua, pp. 112-121, 2002.

[3] Tomy Satria Alasi, "Algoritma Boyer Moore Untuk Penyaringan Pesan Teks Menggunakan Perbandingan Kata Yang Sama,” Semin. Nas. Sains Teknol. Inf., pp. 488-495, 2018.

[4] A. Abimanyu, "Penerapan Algoritma String Matching pada Proses Penyaringan Teks," 2019.

[5] M. Y. Soleh, "Implementasi Algoritma KMP dan Boyer-Moore dalam Aplikasi Search Engine Sederhana," Makal. IF3051 Strateg. Algoritm., 2010.

[6] S. Kristanto, A. Rachmat, and R. G. Santosa, "Implementasi Algoritma Boyer-Moore Pada Permainan Word Search Puzzle,” no. September 2014, pp. 1-8, 2013. 